\title{
ENERGY EXTRACTION FROM AIR OR WATER BY VIBRATIONS
}

\author{
J. Viba, L. Shtals, M. Eiduks \\ Riga Technical University, Institute of Mechanics, \\ 6 Ezermalas Str., Riga, LV 1006, LATVIA \\ e-mail: janis.viba@rtu.lv
}

\begin{abstract}
The paper considers the possibility to derive energy from air or water in a non-traditional way (without using rotating equipment). For this purpose, the authors studied variations in the additional area of a vibrating object in a definite sequence found as the solution of an optimisation problem. In the work, stably moving mechatronic systems were synthesised and modelled, whose control is very simple (not requiring calibration), being a function of the changing sign of phase coordinates.

Key words: Motion control, air/water excitation, optimal control, adaptive control, energy derivation/utilization.
\end{abstract}

\section{INTRODUCTION}

In the daily life, people and equipment are permanently interacting with continuously moving media like air or water. These two media, being renewable energy resources, are highly important for energy production. For this purpose, hydro- and wind power plants with rotating equipment are mostly used. However, energy could be extracted in a simpler way (without using rotating mechanisms) e.g. by vibration [1-5].

In 2007, researchers of the University of Southampton developed a kinetic energy generator, which derives electrical energy from the mechanical vibrations and movements [1]. The generator produces electrical energy using an arrangement of four magnets on a cantilever with a wound coil located in the magnetic field. The magnet size and coil properties are designed to produce energy from low vibration levels and the device has been shown to convert $30 \%$ of the power supplied from the environment into useful electrical power. Communication [2] reports the development of a vibration energy-harvester (PMG27) for the aerospace industry. It harvests the vibration induced by engines or rotor blades to generate electrical power. This enables installation of completely wireless transmission systems incorporating sensors such as those used in health and usage monitoring systems (HUMS), without the need for batteries, expensive cabling or maintenance. A similar vibration energy-harvester (PMG37) for the transportation industry has been reported in [3]. The latest frontier for renewable energy is the ocean floor. For example, a novel method of generating power uses a network of metal rods to tap into the currents that flow along the bottom of the ocean (and along riverbeds as well) [4]. Water swirls as it flows past the rods, making them vibrate. This phenomenon is painfully familiar to oil companies, which spend large sums of money minimizing such vibrations in order to stabilize offshore drilling 
equipment. The cost of water-flow power production is less than that of solar or wind and that of current-based generators [4].

Ocean waves have also been an area of keen interest [5]. There are plenty of design teams out there, working on the perfect tidal turbine, that is, one that can efficiently harness the energy generated by the waves that occur with ebbs and flows of the tides. Many interesting designs are being tested, and several companies are starting to have some success, but there has not yet been much discussion or designs focused on harnessing power from slow moving bodies of water, such as rivers $[4,5]$.

As is known, vibrations cause the object to be pushed and pulled in the directions perpendicular to the current. The mechanical energy that is derivable from these vibrations could then be converted into electricity (the principle of the simplest device for these purposes is outlined in [5]).

In this work, the motion of a vibrator with two degrees of freedom and constant air or water flow $\bar{V}_{0}$ excitation was investigated. The vibrating system shown in Fig. 1 consists of masses $m_{1}, m_{2}$ with springs $c_{1}, c_{12}$ and dampers $b_{1}, b_{12}$.

The main idea was to find out the law of optimal control for variation of additional area $S(t)$ of vibrating mass $m_{2}$ within the following limits:

$$
S_{1} \leq S(t) \leq S_{2},
$$

where: $S_{1}$ is the lower level of additional area of mass $m_{2}$,

$S_{2}$ is the upper level of additional area of mass $m_{2}$,

$t$ is the time.

The criterion of optimization is time $T$ required to move the object from the initial position to the end one [6-14].

To understand the process of fluid excitation and to find the optimal solution for the control problem we will observe a system with one degree of freedom, with mass $m_{1}$ being very large (a massive fundament): $m_{1}>>>m_{2}$.

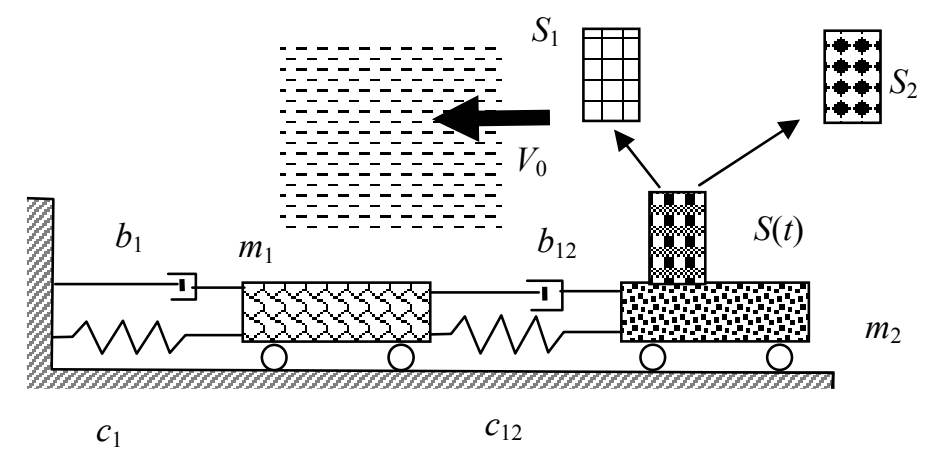

Fig. 1. A model with control over area $S(t)$.

To simplify the differential equation describing the motion of a vibrating object one can omit (for a system with one degree of freedom) the corresponding indices. Then this equation will be written as 


$$
m \ddot{x}=-c x-b \dot{x}-u(t) \cdot\left(V_{0}+\dot{x}\right)^{2},
$$

where: $u(t)=S(t) \cdot k$,

$m=m_{2}$ is the mass,

$\ddot{x}=\ddot{x}_{2}$ is the acceleration,

$x=x_{2} \quad$ is the displacement of the object,

$\dot{x}=\dot{x}_{2} \quad$ is the velocity of object,

$c=c_{12}$ is the stiffness of spring,

$b=b_{12}$ is the damping factor,

$V_{0} \quad$ is the constant velocity of wind,

$S(t) \quad$ is the object's area,

$u(t) \quad$ is the control action,

$k \quad$ is a constant.

It is required to determine the control action $u=u(t)$ for the displacement of system (2) from initial position $x\left(t_{0}\right)$ to end position $x\left(t_{1}\right)$ in the least time (criterion $K=T)$ if area $S(t)$ has limits given by Eq. (1).

\section{SOLUTION OF OPTIMAL CONTROL PROBLEM FOR A SYSTEM WITH ONE DEGREE OF FREEDOM}

For the system excitation the high-speed problem should be solved [9-14]:

$$
K=\int_{t_{0}}^{t_{1}} 1 \cdot d t
$$

Assuming that $t_{0}=0$ and $t_{1}=T$, we have $K=T$.

Equation (2) transforms to the following system:

$$
\begin{aligned}
& \dot{x}_{1}=x_{2} ; \\
& m \dot{x}_{2}=-c x-b \dot{x}-u(t) \cdot\left(V_{0}+\dot{x}\right)^{2},
\end{aligned}
$$

where: $x_{1}=x ; \quad \dot{x}_{1}=x_{2}$,

and Hamiltonian $H$ is [6-8]:

$$
H=\psi_{0}+\psi_{1} x_{2}+\psi_{2} \frac{1}{m} \cdot\left(-c x_{1}-b x_{2}-u(t) \cdot\left(V_{0}+x_{2}\right)^{2}\right),
$$

here $\quad H=\psi \cdot X$, and

$$
\psi=\left\{\begin{array}{l}
\psi_{0} \\
\psi_{1} \\
\psi_{2}
\end{array}\right\} ; \quad X=\left\{\begin{array}{c}
0 \\
x_{2} \\
\frac{1}{m} \cdot\left[-c x_{1}-b x_{2}-u(t) \cdot\left(V_{0}+x_{2}\right)^{2}\right]
\end{array}\right\} .
$$

Scalar multiplication of two last vector functions $\psi$ and $X$ in Eq. (4), at any time instant must be maximal [7-14]. To achieve this maximum, the control action 
$u(t)$ must be within the limits $u(t)=u_{1} ; u(t)=u_{2}$, depending only on the sign of function $\psi_{2}$ (see, e.g. [8-11]):

$$
H=\max H, \text { if } \psi_{2} \cdot\left(-u(t) \cdot\left(V_{0}+x_{2}\right)^{2}\right)=\max .
$$

Therefore, if $\psi_{2}>0,1$ then $u(t)=u_{1}$, and if $\psi_{2}<0$, then $u(t)=u_{2}$, where: $u_{1}=S_{1} \cdot k$ and $u_{2}=S_{2} \cdot k$ (see Eq. (1)).

Examples of a very simple control action (with one and three switch points) are shown in Figs. 2 and 3.

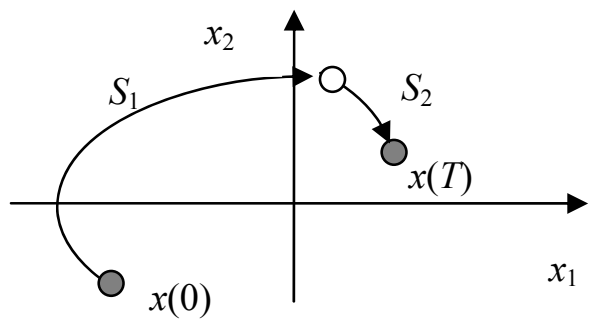

Fig. 2. Optimal control with one switch point.

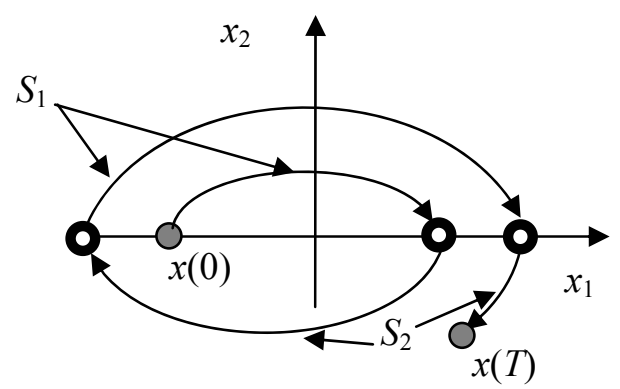

Fig. 3. Optimal control with three switch points at $x_{2}=0$.

The procedure of seeking the switch points (e.g., $\psi_{2}>0$ or $\psi_{2}<0$ ) is reported in [15-17]. The main conclusion following from the optimal control law is that the area at any time must be $S(t)=S_{1}$ or $S(t)=S_{2}$ (according to (1)). In real systems this allows synthesizing quasi-optimal control actions (see, e.g. [17-20]). In addition, it should be mentioned that the optimal control in time domain $u(t)$ in real nonlinear systems without feedback is often unstable. Therefore in this case the task of synthesizing new real control systems include a step of forming control as a mixed function of phase coordinates and time: $\left.u(t)=u\left(x_{1}, x_{2}, t\right)[15-18]\right)$.

\section{OPTIMAL CONTROL PROBLEM FOR A SYSTEM WITH TWO DEGREES OF FREEDOM}

The equation of motion can be described as

$$
\begin{aligned}
& m_{1} \ddot{y}=-c_{1} y-c_{12}(y-z)-b_{1} \dot{y}-b_{12}(\dot{y}-\dot{z}) ; \\
& m_{2} \ddot{z}=c_{12}(y-z)+b_{12}(\dot{y}-\dot{z})-u(t) \cdot\left(V_{0}+\dot{z}\right)^{2},
\end{aligned}
$$


where: $y, \dot{y}, \ddot{y}-$ the displacement, velocity and acceleration of mass $m_{1}$, $z, \dot{z}, \ddot{z}$ - the same for mass $m_{2}$.

To use new variables (phase coordinates), $x_{1}=y, x_{2}=\dot{x}_{1}=\dot{y}, x_{3}=z, x_{4}=\dot{x}_{3}=\dot{z}$, system (6) can be rewritten in the form of a first-order differential equation:

$$
\begin{aligned}
& \dot{x}_{1}=x_{2} ; \\
& \dot{x}_{2}=\frac{1}{m_{1}}\left[-c_{1} x_{1}-c_{12}\left(x_{1}-x_{3}\right)-b_{1} x_{2}-b_{12}\left(x_{2}-x_{4}\right)\right] ; \\
& \dot{x}_{3}=x_{4} ; \\
& \dot{x}_{4}=\frac{1}{m_{2}}\left[c_{12}\left(x_{1}-x_{3}\right)+b_{12}\left(x_{2}-x_{4}\right)-u(t) \cdot\left(V_{0}+x_{4}\right)\right] .
\end{aligned}
$$

In this system with two degrees of freedom the Hamiltonian is [8-13]:

$$
\begin{aligned}
H= & \psi_{0}+\psi_{1} x_{2}+\psi_{2}\left(\frac{1}{m_{1}} \cdot\left(-c_{1} x_{1}-c_{12}\left(x_{1}-x_{3}\right)-b_{1} x_{2}-b_{12}\left(x_{2}-x_{4}\right)\right)+\right. \\
& +\psi_{3} x_{4}+\psi_{4}\left(\frac{1}{m_{2}}\left(c_{12}\left(x_{1}-x_{3}\right)+b_{12}\left(x_{2}-x_{4}\right)-u(t) \cdot\left(V_{0}+x_{4}\right)\right) .\right.
\end{aligned}
$$

The optimal control law is of the same structure as given by (5):

$$
H=\max H, \quad \text { if } \quad \psi_{4} \cdot\left(-u(t) \cdot\left(V_{0}+x_{4}\right)^{2}\right)=\max .
$$

The main conclusion following from the optimal control law (9) for a system with two degrees of freedom is the same as for that with one degree of freedom: the area at any time must be, according to (1), $S(t)=S_{1}$ or $S(t)=S_{2}$.

\section{SYNTHESIS OF A REAL CONTROL ACTION}

For realizing the optimal control actions (in a general case) the system with one degree of freedom needs a feedback with two adapters: one for the displacement measurement and another - for the velocity measurement. A simple case of the control existing with only one adapter when the motion changes directions is shown in Fig. 3 [17]. Existence of such a control action means that it is similar to a negative dry friction, and that the switch points are arranged along the zero velocity line. In that case the equation of motion for high velocity $\left|V_{0}\right| \geq|\dot{x}|$ and dry friction is:

$$
m \cdot \ddot{x}=-c \cdot x-b \cdot \dot{x}-F \cdot \operatorname{sign}(\dot{x})+U(\dot{x}),
$$

where: $U(\dot{x})=-\left[k \cdot\left(V_{0}+\dot{x}\right)^{2} \cdot S_{1} \cdot \frac{1+\operatorname{sign}(\dot{x})}{2}\right]-\left[k \cdot\left(V_{0}+\dot{x}\right)^{2} \cdot S_{2} \cdot \frac{1-\operatorname{sign}(\dot{x})}{2}\right]$, $m$ is the mass,

$c, b, F, k, V_{0}$ are some constants.

Examples of modeling are shown in Figs. 4-7. 


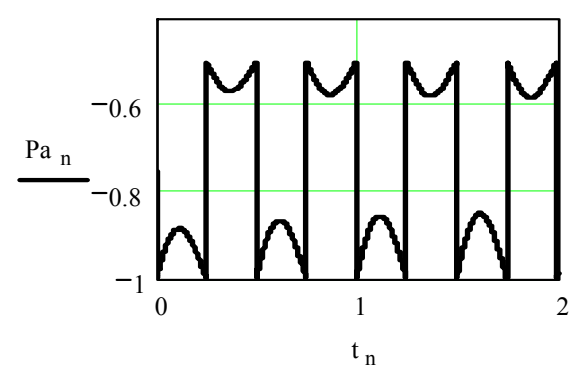

Fig. 4. The full control action $P a_{n}=U(\dot{x})$ Eq. (10) in time $t_{n}$ domain (SI system).

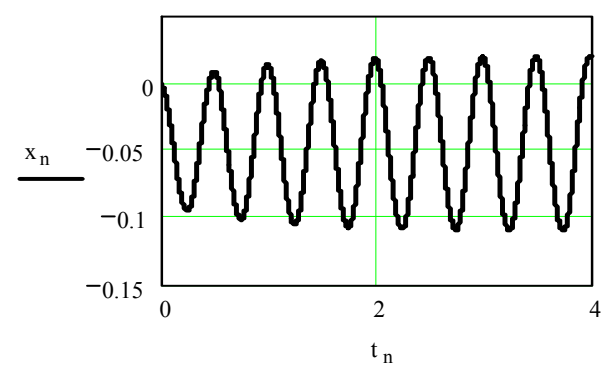

Fig. 5. Displacement $x_{n}$ in time $t_{n}$ domain (SI system).

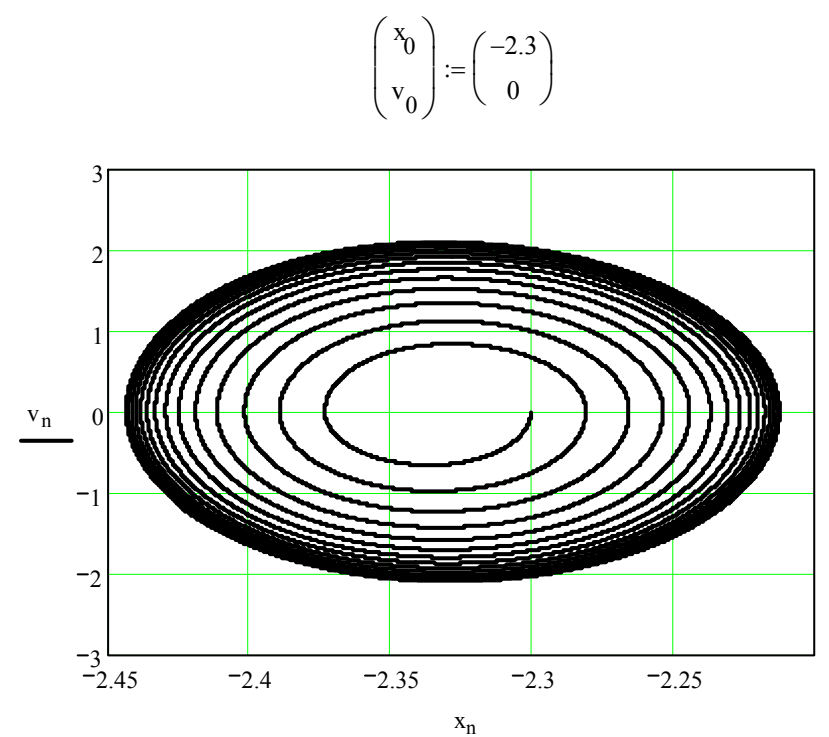

Fig. 6. Motion in the phase plane $\left(x=x_{n} ; \dot{x}=v_{n}\right)$ with initial conditions inside the limit cycle.

$$
\left(\begin{array}{c}
\mathrm{x}_{0} \\
\mathrm{v}_{0}
\end{array}\right):=\left(\begin{array}{c}
-2.0 \\
0
\end{array}\right)
$$

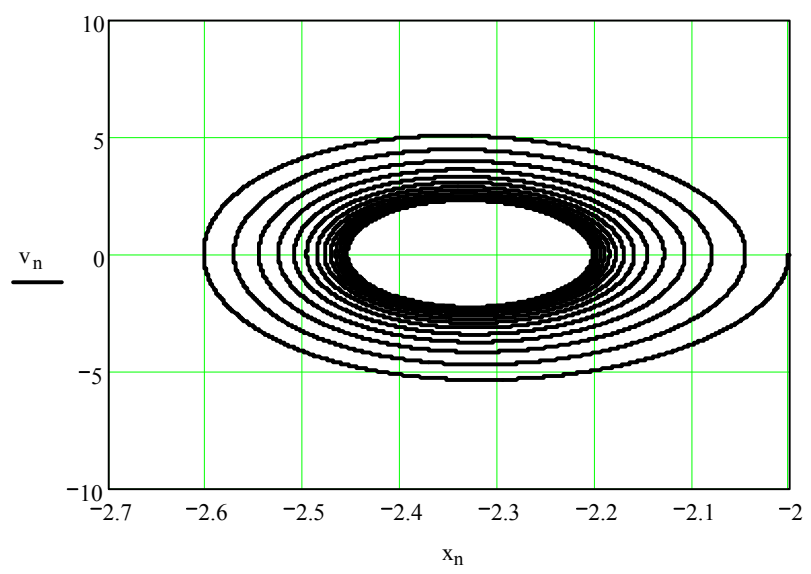

Fig. 7. Motion with initial conditions outside the limit cycle. 
At investigation of a complicated system with a cubic resistance force and dry friction, we made an attempt to find out whether there could exist more than one limit cycle and have obtained the positive answer: for a system with nonperiodical excitation (e.g. at constant velocity $V_{0}$ of air or water flow) more than one limit cycles were revealed (see Figs. 8, 9). Both cycles are separated by different initial conditions.

$$
\begin{aligned}
& m \cdot \ddot{x}=-c \cdot x^{3}-b \cdot \dot{x}-F \cdot \operatorname{sign}(\dot{x})+ \\
& \quad-\left[k \cdot\left(V_{0}+\dot{x}\right)^{2} \cdot S_{2} \cdot \frac{1-\operatorname{sign}(\dot{x})}{2}\right]-\left[k \cdot\left(V_{0}+\dot{x}\right)^{2} \cdot S_{1} \cdot \frac{1+\operatorname{sign}(\dot{x})}{2}\right] .
\end{aligned}
$$

$$
\left(\begin{array}{c}
\mathrm{x}_{0} \\
\mathrm{v}_{0}
\end{array}\right):=\left(\begin{array}{l}
4 \\
0
\end{array}\right)
$$

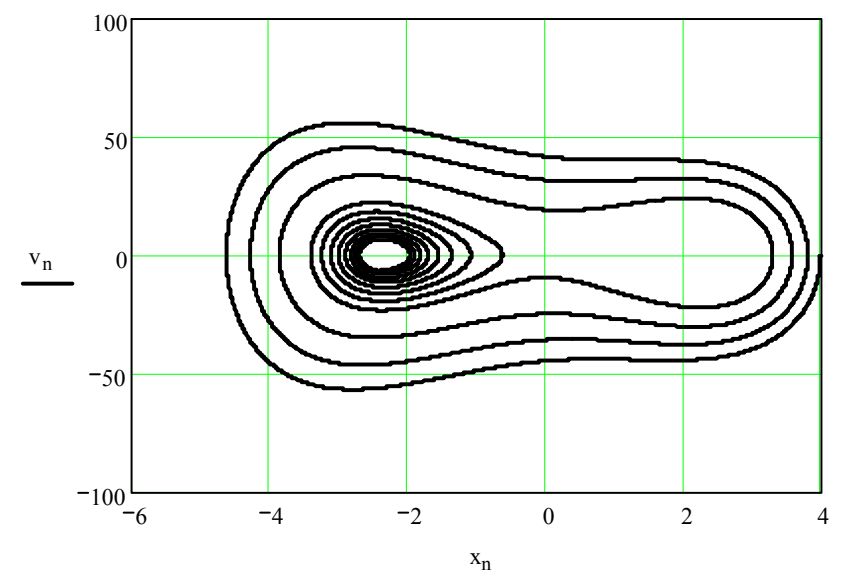

Fig. 8. Motion in the phase plane for the left-side limit cycle.

$$
\left(\begin{array}{c}
\mathrm{x}_{0} \\
\mathrm{v}_{0}
\end{array}\right):=\left(\begin{array}{c}
4 \\
10
\end{array}\right)
$$

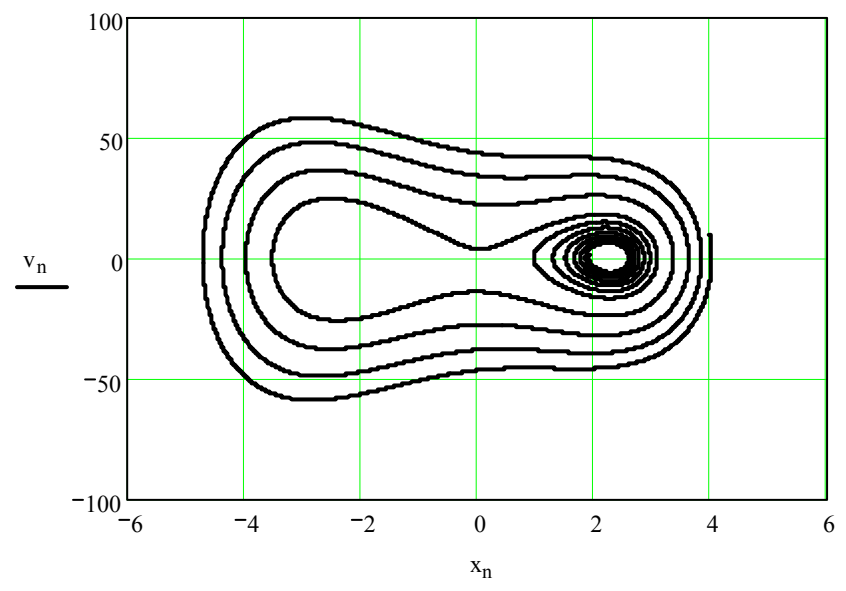

Fig. 9. Motion in the phase plane for the right-side limit cycle. 
The same control action was investigated similar to the above (see (10-11)) for a system with two degrees of freedom:

$$
U(\dot{z})=-\left[k \cdot\left(V_{0}+\dot{z}\right)^{2} \cdot S_{1} \cdot \frac{1+\operatorname{sign}(\dot{z})}{2}\right]-\left[k \cdot\left(V_{0}+\dot{z}\right)^{2} \cdot S_{2} \cdot \frac{1-\operatorname{sign}(\dot{z})}{2}\right] .
$$

The results of modeling are shown in Figs. 10-13.

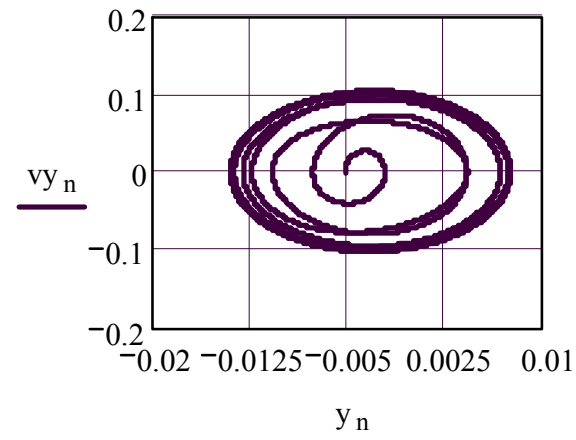

Fig. 10. Motion of mass $m_{1}$ in the phase plane inside the limit cycle.

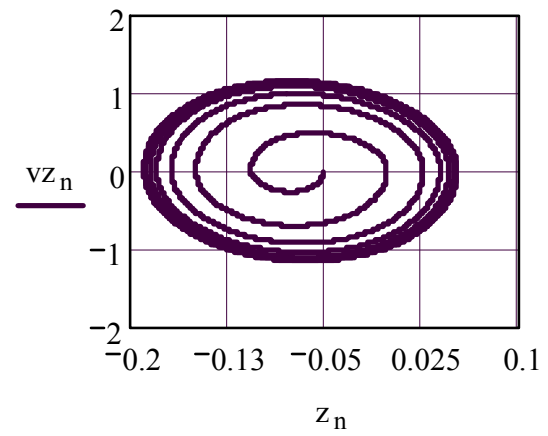

Fig. 11. Motion of mass $m_{2}$ in the phase plane from initial conditions inside the limit cycle.

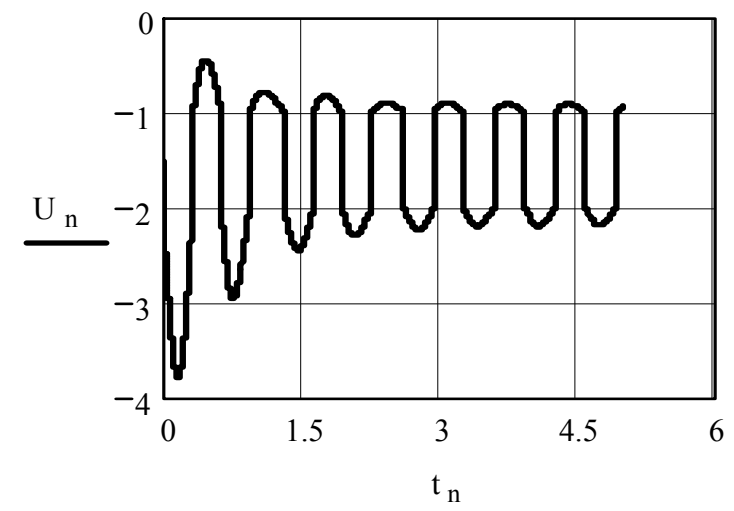

Fig. 12. The control action in the time domain according to Eq. (12).

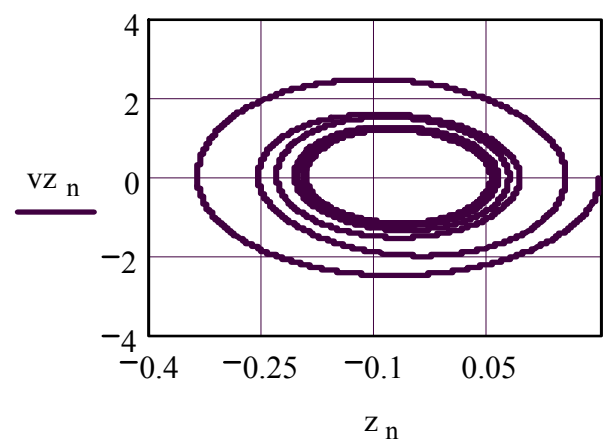

Fig. 13. Motion of mass $\mathrm{m}_{2}$ in the phase plane from initial conditions outside the limit cycle. 
It is shown that the adaptive systems are very stable, because the air excitation and damping forces depend on the velocity to the $2^{\text {nd }}$ power.

In the final stage of investigations some experiments inside a wind tunnel (see Fig. 14) have been analyzed [21]. The parameters of a subsonic wind tunnel were: length, $2.98 \mathrm{~m}$; width, $0.8 \mathrm{~m}$; height, $1.83 \mathrm{~m}$. A variable-speed motor-driven unit downstream the working section permitted a continuous control over the air velocity between 0 and $26 \mathrm{~ms}^{-1}$. The experiments have confirmed that the airflow excitation is very efficient.

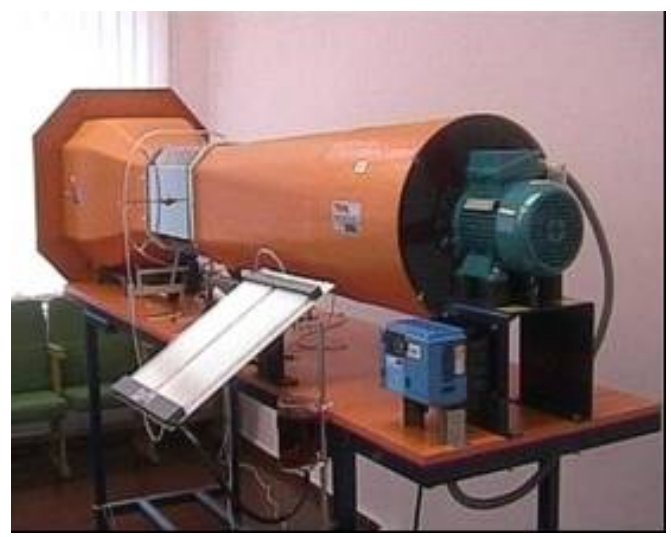

Fig. 14. The wind tunnel.

\section{CONCLUSIONS}

Conclusions that could be drawn from the results of work are as follows. The air or water flow can be used for excitation of an object's motion by vibration. The control of the object area allows very efficient mechatronic systems to be created. The synthesis of the algorithm for strongly non-linear mechanical systems includes the tasks of optimization.

To create a radically new vibration system, adapters and controllers should be used. For this, a very simple control action could be used, which is obtained using the sign functions.

\section{REFERENCES}

1. http://www.gizmag.com/go/7584/.

2. http://www.perpetuum.co.uk/home.php?page_id=12

3. http://www.perpetuum.co.uk/home.php?page_id=13

4. The Weirdest New Source of Alternative Energy: Underwater Vibrations http://discovermagazine.com/2009/mar/25-weirdest-new-source-alternative-energyunderwater-vibrations.

5. http://thegreentechnocrat.com/?p=314.

6. http://en.wikipedia.org/wiki/Lev_Pontryagin (2008).

7. http://en.wikipedia.org/wiki/Pontryagin\%27s_maximum_principle. (February (2008).

8. http://en.wikipedia.org/wiki/Hamiltonian_\%28control_theory\%29. (2007).

9. Boltyanskii, V.G., Gamkrelidze, R.V., \& Pontryagin, L.S. (1956). On the theory of optimum processes. Dokl. AN SSSR, 110, (1), 7-10 (in Russian).

10. Pontryagin, L.S., Boltyanskii, V.G., Gamkrelidze, R.V., \& Mischenko, E.F. (1961). The Mathematical Theory of Optimal Processes, Moscow: Fizmatgiz (in Russian). 
11. Pontryagin, L.S., Boltyanskii, V.G., Gamkrelidze, R.V., \& Mischenko, E.F. (1962). The Mathematical Theory of Optimal Processes. New York: Wiley-Interscience.

12. Boltyanskii, V.G. (1966). Mathematical Methods of Optimal Control. Moscow: Nauka.

13. Boltyanskii, V.G. (1971). Mathematical Methods of Optimal Control (authorized translation from Russian by K.N. Trirogoff). Balskrishnan-Neustadt series. New York: Holt, Rinehart and Winston.

14. Lee, E.B., \& Markus, L. (1972). Foundations of Optimal Control Theory. Moscow: Nauka (in Russian).

15. Lavendelis, E. (1970). Synthesis of optimal vibro-machines. Riga: Zinatne (in Russian).

16. Lavendelis, E., \& Viba, J. (1973). Individuality of Optimal Synthesis of Vibro-Impact Systems. In: Vibrotechnics. Kaunas. Vol. 3 (20). (in Russian).

17. Viba, J. (1988). Optimization and synthesis of vibro-impact systems. Riga: Zinatne (in Russian).

18. Lavendelis, E., \& Viba, J. (2007). Methods of optimal synthesis of strongly non-linear (impact) systems. Scientific Proceedings of Riga Technical University. Mechanics. Vol. 24, Riga.

19. Sonneborn, L., \& Van Vleck, F. (1965). The Bang-Bang Principle for Linear Control Systems, SIAM J. Control, (2), 151-159.

20. http://en.wikipedia.org/wiki/Bang-bang_control. (2008).

21. SUBSONIC WIND TUNNEL C2. http://www.google.lv/ search?hl=lv\&q=RTU+wind+tunnel + specification $\&$ meta $=\& a q=f \& o q=$

\section{ENERGIJAS IEGUVE NO GAISA VAI ŪDENS PLŪSMAS AR VIBRĀCIJU PALİDZĪBU}

J. Vība, L. Štāls, M. Eiduks

$$
\text { Kopsavilkums }
$$

Rakstā aplūkota iespēja iegūt enerǵiju no gaisa vai ūdens plūsmas netradicionālā veidā, nelietojot rotējošas iekārtas. Tam nolūkam izmantota svārstîbu sistēmas objekta papildus laukuma maiņa noteiktā secībā, kas atrasta optimizācijas uzdevuma atrisinājumā. Sintezētas un modelētas stabilas kustības mehatroniskās elektromehāniskās sistēmās (MEMS), kurās vadības sintēzē izmantotas fāžu koordināšu zīmju maiņa.

20.04.2009. 